Fadi Nahab, MD

Tareq Kass-Hout, MD Hashem M. Shaltoni, MD

Correspondence \& reprint requests to Dr. Nahab: fnahab@emory.edu

\section{Periprocedural antithrombotic strategies in acute ischemic stroke interventional therapy}

\section{ABSTRACT}

In patients undergoing endovascular therapy for acute ischemic stroke, antithrombotic therapies are utilized to prevent distal embolization, arterial reocclusion, or catheter-related embolism. However, this must be weighed against the risk of hemorrhagic complications secondary to existing and ongoing ischemia or silent vessel perforation. In this article, we present an overview of the available literature evaluating antithrombotic therapy in patients undergoing endovascular therapy for acute ischemic stroke and discuss the emerging role of these agents. Neurology ${ }^{\circledR} 2012 ; 79$ (Suppl 1):S174-S181

\section{GLOSSARY}

$\mathbf{A C T}=$ activated clotting time; $\mathbf{A D P}=$ adenosine diphosphate; $\mathbf{A I S}=$ acute ischemic stroke; $\mathbf{C l}=\mathbf{c o n f i d e n c e ~ i n t e r v a l ; ~} \mathbf{G P}=$ glycoprotein; IA = intra-arterial; IAT = intra-arterial therapy; IMS = Interventional Management of Stroke; IU = international units; $\mathbf{M C A}=$ middle cerebral artery; $\mathbf{M E R C I}=$ Mechanical Embolus Removal in Cerebral Ischemia; $\mathbf{O R}=$ odds ratio; $\mathbf{P C I}=$ percutaneous coronary intervention; PROACT = Prolyse in Acute Cerebral Thromboembolism; rpro-UK = recombinant prourokinase; rtPA = recombinant tissue plasminogen activator; $\mathbf{s} \mathbf{C H}=$ symptomatic intracerebral hemorrhage; $\mathbf{T I M I}=$ thrombolysis in myocardial ischemia; UK = urokinase.

Intra-arterial therapy (IAT) has emerged as an important adjunct to IV thrombolysis in acute ischemic stroke (AIS). Although IAT has many theoretical advantages, including site specificity and high recanalization rates, early reocclusion and distal embolization occur in 18\%-22\% and $16 \%$, respectively, of the AIS patient population that undergoes endovascular therapy. ${ }^{1-3}$ Periprocedural antithrombotic therapy may be used to reduce these complications, but it must be weighed against the risk of hemorrhagic complications. Here we present an overview of the literature evaluating the utility of antithrombotic therapies for periprocedural support and recanalization in patients undergoing AIS endovascular therapy.

ANTITHROMBOTIC AGENTS FOR PERIPROCEDURAL SUPPORT Anticoagulation therapy. Since the development of percutaneous coronary intervention (PCI), IV unfractionated heparin has remained the primary antithrombotic agent for prevention of periprocedural ischemic complications as a result of its immediate anticoagulation effect, its short half-life, its ability to be monitored with point-of-care testing, and the availability of IV protamine sulfate to rapidly reverse its anticoagulation effect. ${ }^{4,5}$ Unfractionated heparin-mediated inactivation of coagulation proteases (thrombin, factors IXa, Xa, XIa, and XIIa) occurs via its binding to and subsequent activation of antithrombin III (figure 1). ${ }^{6}$ Optimal periprocedural activated clotting time (ACT) in PCI has been empirically determined to range from 250 to 350 seconds (normal, 81-125 seconds), ${ }^{7}$ based on the American College of Cardiology level of evidence C (consensus opinion of experts, case studies, standard of care). ${ }^{8}$ Similarly, there are limited data on the safety of periprocedural heparin in AIS endovascular therapy.

The Prolyse in Acute Cerebral Thromboembolism (PROACT) trial was the first double-blind, randomized, placebo-controlled study of recombinant pro-urokinase (rpro-UK) delivered intra-arterially by microcatheter in acute middle cerebral artery (MCA) ischemic stroke. ${ }^{9}$ The initial 16 patients received a 100-IU (international units)/kg IV bolus of heparin, followed by continuous infusion at a rate of 1,000 IU/hour for 4 hours. At the end of the rpro-UK infusion, $81.8 \%$ of patients treated with this "high-dose heparin" demonstrated recanalization (thrombolysis in myocardial ischemia score [TIMI], $2+3$ ), with an associated symptomatic intracerebral hemorrhage (sICH) rate of $27.3 \%$. The heparin regimen was modified for the remaining patients on the recommendation

From Emory University (F.N.), Atlanta, GA; State University of New York at Buffalo (T.K.), Buffalo, NY; and Baylor College of Medicine (H.M.S.), Houston, TX.

Go to Neurology.org for full disclosures. Disclosures deemed relevant by the authors, if any, are provided at the end of this article. 


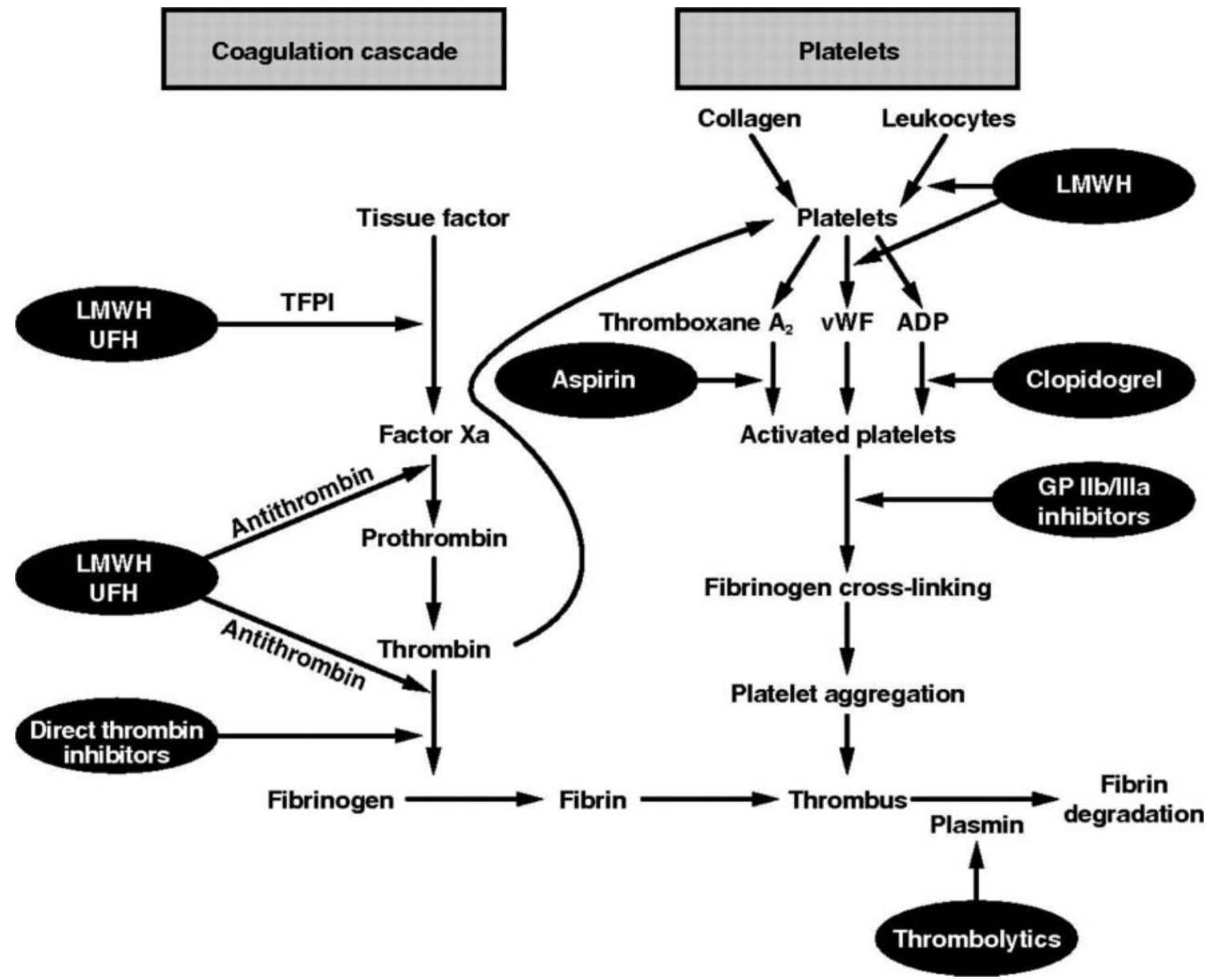

Graphic of coagulation cascade shows main sites of action of antithrombin therapies. ADP = adenosine diphosphate; GP $=$ glycoprotein; $L M W H=$ lowmolecular-weight heparin; TFPI = tissue factor pathway inhibitor; UFH = unfractionated heparin; vWF = von Willebrand factor. Reprinted with permission by Elsevier, from: Selwyn AP. Prothrombotic and antithrombotic pathways in acute coronary syndromes. Am J Cardiol 2003;91:3H-11H.

of the External Safety Committee and Drs. Jack Hirsh, Gregory del Zoppo, and Anthony Furlan. The bolus dose and infusion rates were lowered to $2,000 \mathrm{IU}$ and $500 \mathrm{IU} /$ hour, respectively. In patients treated with rproUK, the "low-dose heparin" regimen effectively cut the sICH and MCA recanalization rates to $6.7 \%$ and $40 \%$, respectively (personal communication, A. Furlan, January 2010).

Subsequently, multiple IAT trials evaluating endovascular therapy in AIS have relied on a low-dose heparin regimen similar to that of the PROACT trial. The previously effective low-dose heparin protocol was also shown to be effective in eliciting a recanalization and sICH rate of $66 \%$ and $10 \%$, respectively, in PROACT II, a phase III trial designed to assess the clinical efficacy and safety of intraarterial (IA) rpro-UK in acute MCA ischemic stroke of less than 6-hour duration. ${ }^{10}$ Moreover, a low-dose IV regimen (2,000 IU bolus followed by $450 \mathrm{IU} /$ hour), in addition to a heparin flush (40 IU/hour, administered via access sheath and guide catheter), was used in the Interventional Management of Stroke (IMS) I and II trials. ${ }^{11,12}$ These trials, designed to assess whether a combined IV/IAT approach to recanalization was superior to standard IV rtPA alone in AIS, found that recanalization rates (TIMI $2+3$ ) were similar (IMS I: 56\%; IMS II: 60\%), with rates of sICH comparable to those in other endovascular acute stroke studies (IMS I: 6.3\%; IMS II: 9.9\%). ${ }^{11,12}$ The ongoing IMS III study uses the same heparin regimen used in IMS I and IMS II. ${ }^{13}$

Recently, the safety of low-dose heparin, when combining mechanical devices with IV or IA thrombolytic therapy, has been further demonstrated in multiple prospective, multicenter single-arm mechanical embolectomy trials. In the Mechanical Embolus Removal in Cerebral Ischemia (MERCI) trial, 164 patients with large-vessel stroke underwent thrombectomy with the Merci retriever device within 8 hours of symptom onset, including 48 patients (29.3\%) who received IV rtPA before intervention. ${ }^{14}$ Periprocedural heparin was given at the 


\begin{tabular}{|c|c|c|c|}
\hline \multicolumn{4}{|c|}{ Doses of periprocedural heparin used in acute ischemic stroke endovascular trials } \\
\hline Trial name & Heparin IV bolus dose & Heparin IV infusion dose & Heparin IA \\
\hline $\begin{array}{l}\text { Prolyse in Acute Cerebral } \\
\text { Thromboembolism (PROACT I) }\end{array}$ & Remaining patients: $2,000 \mathrm{IU}$ & $\begin{array}{l}\text { Remaining patients: } 500-\mathrm{IU} / \mathrm{h} \\
\text { infusion for } 4 \mathrm{~h}\end{array}$ & \\
\hline $\begin{array}{l}\text { Prolyse in Acute Cerebral } \\
\text { Thromboembolism (PROACT II) }\end{array}$ & $2,000 \mathrm{IU}$ & $500-I U / h$ infusion for $4 \mathrm{~h}$ & None \\
\hline $\begin{array}{l}\text { Interventional Management } \\
\text { of Stroke (IMS I, II, and III) }{ }^{11-13}\end{array}$ & $2,000 \mathrm{IU}$ & $\begin{array}{l}450-I U / h \text { infusion for the time } \\
\text { of the procedure }\end{array}$ & $\begin{array}{l}40-I U / h \text { infusion for the } \\
\text { time of the procedure }\end{array}$ \\
\hline $\begin{array}{l}\text { Mechanical Embolus Removal } \\
\text { in Cerebral Ischemia (MERCI) }\end{array}$ & $\begin{array}{l}\text { Allowed at the discretion of the } \\
\text { investigator }\end{array}$ & $\begin{array}{l}\text { Allowed at the discretion of } \\
\text { the investigator }\end{array}$ & None \\
\hline \multirow[t]{2}{*}{$\begin{array}{l}\text { Study of the Penumbra } \\
\text { System }^{16}\end{array}$} & $\begin{array}{l}\text { Subjects without IV thrombolytic } \\
\text { treatment: 5,000 IU }\end{array}$ & $\begin{array}{l}\text { Subjects without IV thrombolytic } \\
\text { treatment: continuous infusion at } \\
2,000-I U / \text { hour to maintain an } \\
\text { ACT } \geq 250 \text { seconds }\end{array}$ & None \\
\hline & $\begin{array}{l}\text { Subjects with IV thrombolytic } \\
\text { treatment: } 2,000 \mathrm{IU}\end{array}$ & $\begin{array}{l}\text { Subjects with IV thrombolytic } \\
\text { therapy: continuous infusion at } \\
1,000-\mathrm{IU} / \text { hour }\end{array}$ & \\
\hline
\end{tabular}

Abbreviations: $A C T=$ activated clotting time; $I A=$ intra-arterial; $I U$ = international units.

discretion of the treating interventionalist, and data on periprocedural heparin use was collected on consecutive patients enrolled in the final 6 months of the study. Of the 51 patients enrolled during this study period, 24 (47\%) received periprocedural IV heparin, with a median dose of 3,000 IU, including 8 patients who received IV rtPA. In a post hoc analysis, there was no significant difference in rates of revascularization success, hemorrhage, procedural complications, or 90-day mortality between patients receiving heparin and those not receiving heparin. In multivariable analysis, a 90-day good outcome (modified Rankin Scale score, $0-2$ ) was associated with periprocedural heparin use (odds ratio [OR] 5.89; $95 \%$ confidence interval $[\mathrm{CI}] 1.34-25.92 ; p=$ 0.0189). ${ }^{15}$

In the phase I study of the Penumbra System, 20 patients received treatment with mechanical embolectomy, including 6 patients who received IV rtPA and 9 patients who received postdevice IA rtPA. ${ }^{16}$ Heparin (2,000-IU bolus, followed by 1,000-IU/hour continuous infusion) was administered systemically to patients who received thrombolytic therapy. Patients who did not receive thrombolytic therapy were administered a higher bolus dose (5,000 IU) and infusion rate (continuous infusion of 2,000 IU/hour) to maintain ACT of a least 250 seconds. Recanalization (TIMI 2-3) before IA lysis was achieved in all treated cases, and 2 patients (10\%) developed sICH. ${ }^{16}$

Table 1 summarizes the doses of periprocedural heparin used in AIS endovascular trials.

Antiplatelet therapy. Platelet adhesion and aggregation are central features of arterial thrombosis and arterial reocclusion. ${ }^{2}$ The inhibitory effect of conven- tional antiplatelet drugs, including aspirin and adenosine diphosphate (ADP) analogues (clopidogrel or ticlopidine), are dependent on inhibition of prostaglandin synthesis or signal transduction pathways induced by activated ADP receptors (figure 2).

The evolution of intracranial stenting for AIS highlights the importance of adequate platelet inhibition for periprocedural support to prevent stent thrombosis. In the first US Food and Drug Administration-approved prospective study on primary intracranial stenting for AIS, ${ }^{17}$ preprocedural oral antiplatelet therapy included clopidogrel, $600 \mathrm{mg}$, and aspirin, $650 \mathrm{mg}$ (oral or rectal), combined with intraprocedural heparin to achieve an ACT between 250 and 300 seconds. Recanalization (TIMI 2 or 3 ) was achieved in all 20 patients, with $1(5 \%)$ symptomatic and $2(10 \%)$ asymptomatic hemorrhages. No stent thrombosis occurred in the study.

Rapid onset of the full antiplatelet effect of aspirin and clopidogrel is essential when performing urgent intracranial stenting to reduce the risk of stent thrombosis. Studies on the optimal dosing of aspirin and clopidogrel have been extrapolated from PCI data. For patients not already on chronic aspirin therapy, 300 to $325 \mathrm{mg}$ of aspirin at least 2 hours before PCI is recommended ${ }^{18}$; for patients not on chronic clopidogrel therapy, loading with $600 \mathrm{mg}$ has been shown to achieve the full antiplatelet effect within 2 hours of administration, to result in higher plasma concentrations of the active metabolite, and to significantly lower ADP-induced platelet aggregation in comparison with a loading dose of $300 \mathrm{mg}$; loading doses of $900 \mathrm{mg}$ have not been shown to result in significantly more antiplatelet effects. ${ }^{19-22}$ 


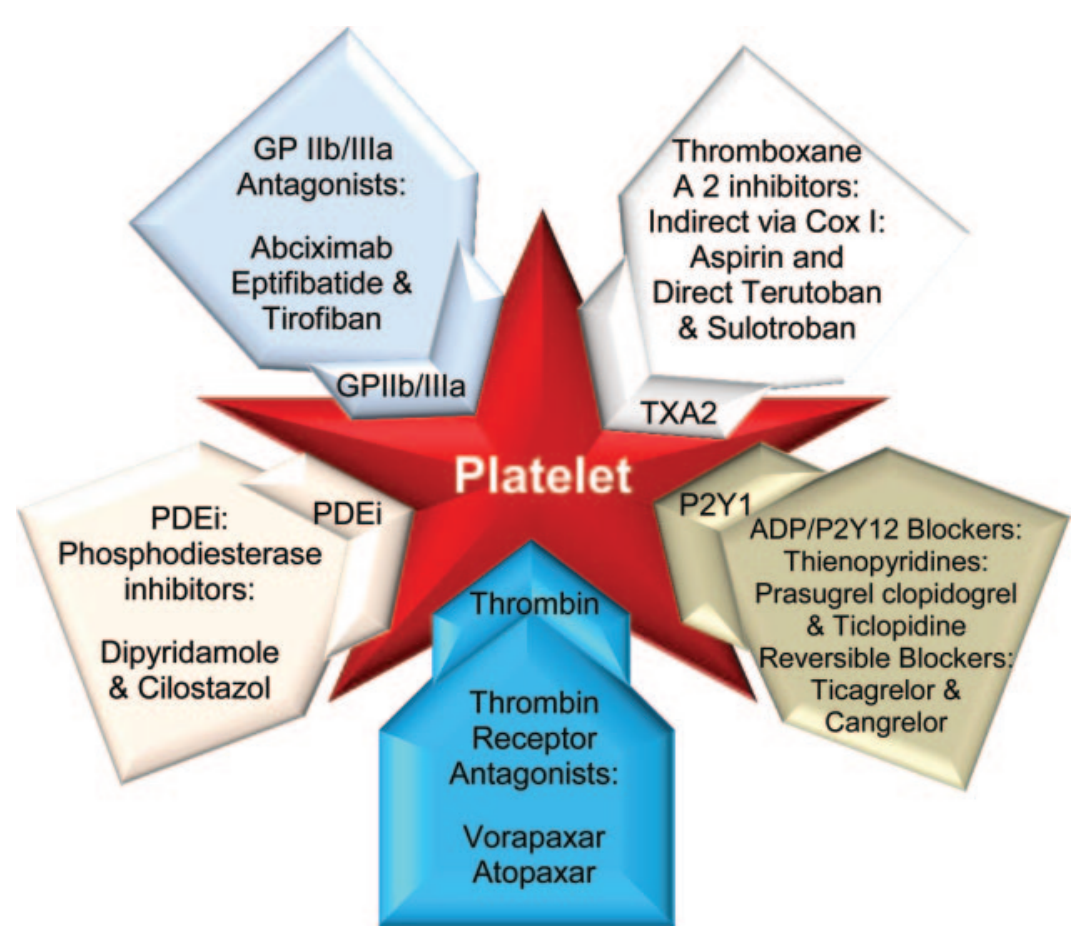

$\mathrm{ADP}=$ adenosine diphosphate; $\mathrm{GP}=$ glycoprotein; $\mathrm{PDEi}=$ phosphodiesterase inhibitor; TXA2 = thromboxane A2.
Thrombosis And Safety (GRAVITAS) trial evaluating patients undergoing elective PCI. ${ }^{29}$ Patients identified by the VerifyNow assay as nonresponders to clopidogrel were randomly assigned to high-dose (repeat $600-\mathrm{mg}$ load, followed by $150 \mathrm{mg}$ daily) or standard-dose (75 mg daily) clopidogrel 1 day after PCI. There was no difference between the 2 treatment arms in cardiovascular outcomes, including death and stent thrombosis, at 30 days and 6 months. Although individualizing antiplatelet therapy on the basis of platelet function testing is appealing, routine platelet function testing is not currently recommended in $\mathrm{PCI}^{30,31}$ and requires study in AIS endovascular therapy.

Newer oral antiplatelet agents such as prasugrel, which requires only 1 hepatic CYP450 oxidation step to generate its active metabolite, and ticagrelor, which is rapidly absorbed as an active metabolite without requiring any hepatic or intestinal oxidative biotransformation, may be more effective in patients who have loss-of-function alleles. ${ }^{31}$ However, prasugrel is currently contraindicated in patients with a history of stroke or TIA, after a post hoc analysis in acute coronary syndrome patients identified a higher rate of the combined endpoint of death from any cause, nonfatal myocardial infarction, nonfatal stroke, or nonfatal major bleeding in comparison with clopidogrel (hazard ratio 1.54; 95\% CI 1.02$2.32 ; p=0.04), 32,33$ and ticagrelor has not been evaluated in stroke patients. a loading dose of $600 \mathrm{mg}$ of clopidogrel prior to initiating a regular dose of $75 \mathrm{mg} /$ day was not associated with hemorrhagic transformation in any of the patients. ${ }^{23}$

It has been recognized that the response to clopidogrel varies among patients. ${ }^{24,25}$ Clopidogrel is a prodrug that requires oxidation by hepatic CYP 450 enzymes to generate the active metabolite that inhibits the platelet for its lifespan. The majority of clopidogrel is inactivated by carboxylesterases, such that only $15 \%$ of the active metabolite reaches the platelet receptor after undergoing 2 steps of oxidative biotransformation. As a result, loss-of-function alleles in the gene encoding CYP450 2C19 can significantly lower levels of the active metabolite of clopidogrel, and patients with these loss-of-function alleles who undergo PCI have been shown to have increased cardiovascular events, including stent thrombosis, in comparison with extensive metabolizers. ${ }^{26-28}$ The impact of clopidogrel resistance in AIS endovascular therapy remains largely unstudied.

The use of platelet function testing has been considered one potential approach to identify patients with clopidogrel resistance and to individualize therapy. This concept was evaluated in the Gauging Responsiveness with a VerifyNow (Accumetrics, Inc., Corporation, San Diego, CA) assay-Impact on

\section{ANTITHROMBOTIC AGENTS FOR RECANALIZATION}

IV antiplatelet agents. Because the final common event in platelet aggregation requires binding of fibrinogen to the glycoprotein (GP) IIb/IIIa complex, agonist pathways activating the GP IIb/IIIa complex that are not affected by aspirin or ADP analogues are still able to potentiate platelet aggregation. ${ }^{34} \mathrm{Al}-$ though the GP IIb/IIIa inhibitors abciximab, eptifibatide, and tirofiban have undergone large clinical trials in PCI to establish their safety and effectiveness, data on their role in patients with AIS undergoing IAT is limited to only 4 case series that have included $\geq 10$ patients and 2 prospective studies of patients treated with combination thrombolysis and abciximab. ${ }^{35-40}$

In one AIS study, a total of 26 patients were treated with IA urokinase (UK), with or without IV abciximab $(0.25-\mathrm{mg} / \mathrm{kg}$ bolus, then $0.125-\mu \mathrm{g} / \mathrm{kg} /$ min periprocedural infusion). ${ }^{35}$ Patients who received both treatments had significantly higher recanalization rates (TIMI $2+3$ ) than patients treated with IA UK alone (UK + abciximab $90 \%$ vs UK $43.8 \%$; $p=0.037$ ), with no significant difference in sICH (UK + abciximab, 16\%, vs UK, $30 \%$; 
$p=1.0) .{ }^{35}$ Patients who received abciximab also required significantly lower amounts of UK to achieve recanalization than patients treated with UK alone (418,000 IU vs 828,000 IU; $p<0.005)$. In another series, 12 AIS patients refractory to IV or IA thrombolysis, were given an IV or IA abciximab bolus (mean, $11.8 \pm 5.8 \mathrm{mg}$ ) in addition to angioplasty, mechanical embolectomy, or stenting; 11 patients (92\%) had successful recanalization (TIMI $2+3$ ), with 1 instance $(8.3 \%)$ of sICH. ${ }^{36}$ GP IIb/IIIa inhibitors were also evaluated as adjunctive therapy for patients with large-vessel occlusion and AIS refractory to pharmacologic thrombolysis with rtPA and mechanical disruption, balloon angioplasty, or both. Twenty-one patients with large-vessel occlusion refractory to IAT were treated with IV or IA GP IIa/ IIIb inhibitors, with recanalization (TIMI $2+3$ ) achieved in 17 (81\%) and no cases of sICH. ${ }^{37} \mathrm{IV}$ tirofiban has also been evaluated in combination with heparin and followed by IA urokinase in 21 AIS patients ${ }^{38}$; recanalization (TIMI $2+3$ ) was achieved in 17 patients $(81 \%)$, although sICH occurred in 5 patients (24\%) and included 3 fatal hemorrhages. $\mathrm{Al}$ though these case series suggested high recanalization rates associated with the use of GP IIb/IIIa inhibitors in IAT, the risk of sICH associated with their use remained a concern.

The Combined Local Fibrinolysis and IV Abciximab in Acute Vertebrobasilar Stroke Treatment (FAST) multicenter study prospectively evaluated IV abciximab $(0.25 \mathrm{mg} / \mathrm{kg})$ followed by a 12 -hour infusion $(0.125 \mu \mathrm{g} / \mathrm{kg} / \mathrm{min})$ and low-dose IA rtPA (median dose, $20 \mathrm{mg}$ ) in patients with acute vertebrobasilar occlusion; additional angioplasty/stenting was allowed if there was severe residual stenosis. ${ }^{39} \mathrm{Of}$ 47 patients, 34 (72\%) achieved recanalization (TIMI $2+3)$, though 14 patients required angioplasty/ stenting; sICH occurred in 6 patients (13\%), all of whom died. In another prospective study, the combination of IV abciximab $(0.25-\mathrm{mg} / \mathrm{kg}$ bolus, followed by $0.125 \mu \mathrm{g} / \mathrm{kg} / \mathrm{min}$ ) with escalating doses of IA reteplase $(0.5,1,1.5,2$ units) was evaluated in AIS patients 3 to 6 hours after symptom onset as part of an open-label, dose-ranging, phase I study. ${ }^{40}$ Twenty patients were recruited; 18 successfully received IV abciximab with escalating doses of IA reteplase, and 2 patients had premature discontinuations due to sICH or pseudothrombocytopenia. Recanalization (defined as an improvement by 1 or more grades from baseline) was achieved in 13 patients (65\%), and 1 patient had sICH (5\%). The safety stopping rule was not activated in any of the tiers. ${ }^{40}$ Together these prospective studies demonstrated high recanalization rates associated with the use of GP IIb/IIIa inhibitors in IAT with a moderate risk of sICH.
Although other case series also suggest that IV abciximab may be effective in the treatment of arterial reocclusion after initial recanalization in AIS, 2,3,41 data from the Multi-MERCI Trial, part 1, suggest caution is warranted in the use of abciximab to complement AIS endovascular therapy. Major protocol violations in this study included 9 patients who were treated with IV abciximab, and its use was associated with asymptomatic subarachnoid hemorrhage (OR 19.2; $95 \%$ CI 3.68 to $>100) .{ }^{42}$ Additionally, a recent multicenter series including 12 AIS patients undergoing IAT with adjunctive IV or IA abciximab resulted in sICH in $3(25 \%){ }^{43}$ The use of GP IIb/ IIIa inhibitors in AIS patients undergoing IAT remains investigational and of uncertain benefit.

Oral antiplatelet agents. Although pooled analyses from 2 large, randomized, placebo-controlled trials have shown a modest but statistically significant benefit from aspirin in the prevention of recurrent stroke events when initiated within 48 hours of ischemic stroke, ${ }^{44}$ aspirin administration is contraindicated for 24 hours after IV thrombolysis. ${ }^{45,46}$ The optimal timing to initiate oral antiplatelets in AIS patients who do not receive IV thrombolysis and undergo endovascular therapy has yet to be systematically evaluated. The majority of endovascular trials in AIS have prohibited the administration of antiplatelet agents or anticoagulants for 24 hours posttreatment. ${ }^{9-13}$ The MERCI and Multi-MERCI studies allowed 325 mg of aspirin to be given orally or rectally at the end of the embolectomy procedure, with no oral/IV anticoagulation administered in the first 24 hours posttreatment.

DISCUSSION Optimal doses of heparin and antiplatelet therapies for periprocedural support during AIS endovascular therapy have not been established. However, these data suggest that a low-dose heparin regimen (2,000-IU bolus followed by a 500-IU/hour continuous infusion) may be safe in cases where IV rtPA has been administered. In cases where mechanical embolectomy is performed, without prior IV rtPA administration, a higher-dose heparin regimen (5,000-IU bolus followed by a 2,000 -IU/hour continuous infusion, to maintain ACT $\geq 250$ seconds) may be considered. Periprocedural support for intracranial stenting in AIS requires adequate platelet inhibition to reduce the risk of stent thrombosis and can be achieved with loading doses of aspirin, 300 to $650 \mathrm{mg}$, and clopidogrel, $600 \mathrm{mg}$. The role of platelet function testing in AIS endovascular therapy requires further study before its routine use can be recommended.

The safety and efficacy of IV and oral antiplatelets to augment recanalization in AIS endovascular ther- 
Table 2 Dosing table for anticoagulant and antiplatelet therapy during endovascular therapy for acute ischemic stroke

\begin{tabular}{|c|c|c|}
\hline \multirow[b]{2}{*}{ Drug } & \multicolumn{2}{|l|}{ During endovascular therapy } \\
\hline & Patient received IV thrombolytic & $\begin{array}{l}\text { Patient did not receive IV thrombolytic, } \\
\text { and IA thrombolytic use anticipated }\end{array}$ \\
\hline \multicolumn{3}{|l|}{ Parenteral anticoagulants } \\
\hline Unfractionated heparin & $\begin{array}{l}\text { May consider } 2,000-\mathrm{IU} \text { bolus followed by } \\
500-\mathrm{IU} / \mathrm{h} \text { continuous infusion throughout } \\
\text { procedure }\end{array}$ & $\begin{array}{l}\text { May consider } 5,000-\mathrm{IU} \text { bolus followed by a } \\
2,000-\mathrm{IU} / \mathrm{h} \text { continuous infusion throughout } \\
\text { the procedure to achieve target } \mathrm{ACT} \geq 250 \\
\text { seconds }^{\mathrm{b}}\end{array}$ \\
\hline \multicolumn{3}{|c|}{$\begin{array}{l}\text { Glycoprotein Ilb/IIla receptor } \\
\text { antagonists }^{c}\end{array}$} \\
\hline Abciximab & Of uncertain benefit & $\begin{array}{l}\text { Of uncertain benefit; may consider in } \\
\text { patients who have arterial reocclusion } \\
\text { after initial recanalization; LD of } 0.25 \mathrm{mg} / \\
\mathrm{kg} \text { IV bolus, MD of } 0.125 \mu \mathrm{g} / \mathrm{kg} \text { per minute } \\
\text { (maximum } 10 \mu \mathrm{g} / \mathrm{min} \text { ) }\end{array}$ \\
\hline Tirofiban & Of uncertain benefit & $\begin{array}{l}\text { Of uncertain benefit; LD of } 0.4 \mu \mathrm{g} / \mathrm{kg} / \mathrm{min} \\
\text { IV bolus, MD of IV infusion of } 0.1 \mu \mathrm{g} / \mathrm{kg} / \\
\text { min; reduce rate of infusion by } 50 \% \text { in } \\
\text { patients with estimated creatinine } \\
\text { clearance }<30 \mathrm{~mL} / \mathrm{min}\end{array}$ \\
\hline Oral antiplatelet agents & $\begin{array}{l}\text { Avoid for } 24 \mathrm{~h} \text { after IV thrombolytic } \\
\text { therapyc }\end{array}$ & $\begin{array}{l}\text { May consider initiating immediately after } \\
\text { endovascular therapyd; LD of aspirin, 300- } \\
650 \mathrm{mg} \text {, and clopidogrel, } 600 \mathrm{mg} \text {, for } \\
\text { patients undergoing intracranial stenting } \\
\text { and not on chronic aspirin and clopidogrel } \\
\text { therapye }\end{array}$ \\
\hline
\end{tabular}

Abbreviations: $A C T$ = activated clotting time; IU = international units; $L D=$ loading dose; $M D=$ maintenance dose. ${ }^{a}$ Based on Prolyse in Acute Cerebral Thromboembolism (PROACT) ${ }^{9}$ and PROACT II trials. ${ }^{10}$

${ }^{b}$ Based on the prospective study of the Penumbra system. ${ }^{34-43}$

${ }^{c}$ Based on the National Institute of Neurological Disorders and Stroke (NINDS) tPA Stroke Study ${ }^{45}$ and the European Cooperative Acute Stroke Study (ECASS) 3 trial. 46

${ }^{\mathrm{d}}$ Based on the Mechanical Embolus Removal in Cerebral Ischemia (MERCI) trial ${ }^{42}$ and the Multi-MERCI trial. ${ }^{14}$

e Based on the Stent-Assisted Recanalization in Acute Ischemic Stroke (SARIS) trial. ${ }^{17}$

apy has not been established. Although preliminary studies suggest that IV antiplatelet therapies may augment recanalization in AIS endovascular therapy when combined with IV or IA thrombolytic therapy, the risk of hemorrhagic complications remains a concern and further prospective studies are needed before their use can be recommended. Oral antiplatelet therapies remain contraindicated for 24 hours after IV thrombolytic therapy; however, early initiation may be considered after AIS endovascular therapy, especially in patients who have undergone mechanical embolectomy without IA thrombolysis. Our recommended strategies for periprocedural anticoagulants and antiplatelet therapies in AIS endovascular therapy are summarized in table 2.

CONCLUSION Despite the availability of multiple antithrombotic agents, many questions remain on the optimal use of these agents for AIS endovascular therapy, as evidenced by the lack of uniformity among studies to date. Although periprocedural anticoagulant and antiplatelet therapies have been demonstrated to reduce periprocedural thrombotic complications in PCI, further studies are warranted in AIS to define their optimal use and dosing during IAT when balanced against their risk of hemorrhage.

\section{AUTHOR CONTRIBUTIONS}

Dr. Nahab: drafting/revising the manuscript, study concept or design, analysis or interpretation of data. Dr. Kass-Hout: drafting/revising the manuscript. Dr. Shaltoni: drafting/ revising the manuscript, acquisition of data.

\section{ACKNOWLEDGMENT}

The authors thank Sara Berentsen for assistance with editing.

\section{DISCLOSURE}

Dr. Nahab received honoraria from the National Stroke Association and Imedex. Dr. Kass-Hout has received study funding from Genentech Medical Education Department, which provided the study drug for the trial Wake Up Symptomatic Stroke in Acute Brain Ischemia (WASSABI), of which Dr. Kass-Hout is primary investigator. Dr. Shaltoni reports no disclosures. Go to Neurology.org for full disclosures.

Received August 28, 2011. Accepted in final form November 18, 2011.

\section{REFERENCES}

1. Qureshi AI, Siddiqui AM, Kim SH, et al. Reocclusion of recanalized arteries during intra-arterial thrombolysis for 
acute ischemic stroke. AJNR Am J Neuroradiol 2004;25: 322-328.

2. Heo JH, Lee KY, Kim SH, Kim DI. Immediate reocclusion following a successful thrombolysis in acute stroke: a pilot study. Neurology 2003;60:1684-1687.

3. Janjua N, Alkawi A, Suri MFK, Qureshi AI. Impact of arterial reocclusion and distal fragmentation during thrombolysis among patients with AIS. AJNR Am J Neuroradiol 2008;29:253-258.

4. Grutzig AR, Senning A, Siegenthaler WE. Nonoperative dilatation of coronary-artery stenosis: percutaneous transluminal coronary angioplasty. N Engl J Med 1979; 301:61-68.

5. Hirsh J, Bauer KA, Donati MB, Gould M, Samama MM, Weitz JI. Parenteral anticoagulants: American College of Chest Physicians Evidence-Based Clinical Practice Guidelines (8th edition). Chest 2008;133:141S-159S.

6. Rosenberg R, Bauer K. The Heparin-Antithrombin System: A Natural Anticoagulant Mechanism, 3rd ed. Philadelphia: Lippincott; 1994.

7. Hemochron Activated Clotting Time package insert. Available at: www.itcmed.com/getattachment/28a287865e9a-48d1-a54d-5a23a2466955/ITC-HEMOCHRONCuvette-Package-Inserts-ACT-PLUS-Ass.aspx. Accessed October 9, 2011.

8. Kushner FG, Hand M, Smith SC, et al. 2009 Focused updates: ACC/AHA guidelines for the management of patients with ST-elevation myocardial infarction and ACC/AHA/ SCAI guidelines on percutaneous coronary intervention. J Am Coll Cardiol 2009;54:2205-2241.

9. del Zoppo GJ, Higashida RT, Furlan AJ, et al. PROACT: a phase II randomized trial of recombinant pro-urokinase by direct arterial delivery in acute middle cerebral artery stroke: PROACT investigators: Prolyse in Acute Cerebral Thromboembolism. Stroke 1998;29:4-11.

10. Furlan A, Higashida R, Wechsler L, et al. Intra-arterial prourokinase for acute ischemic stroke: the PROACT II study: a randomized controlled trial. JAMA 1999;282: 2003-2011.

11. IMS Study Investigators. Combined intravenous and intra-arterial recanalization for acute ischemic stroke: the Interventional Management of Stroke study. Stroke 2004; 35:904-911.

12. Tomsick T, Broderick J, Carrozella J, et al. Revascularization results in the Interventional Management of Stroke II trial. Am J Neuroradiol 2008;29:582-587.

13. Khatri P, Hill MD, Palesch YY, et al. Methodology of the Interventional Management of Stroke III trial. Int J Stroke 2008;3:130-137.

14. Smith WS, Sung G, Saver J, et al. Mechanical thrombectomy for acute ischemic stroke: final results of the Multi MERCI trial. Stroke 2008;39:1205-1212.

15. Nahab F, Walker GA, Dion JE, Smith WS. Safety of periprocedural heparin in acute ischemic stroke endovascular therapy: the Multi MERCI trial. J Stroke Cerebrovasc Dis Epub 2011 Jun 1.

16. Bose A, Henkes H, Alfke K, et al. The Penumbra system: a mechanical device for the treatment of acute stroke due to thromboembolism. AJNR Am J Neuroradiol 2008;29: 1409-1413.

17. Levy El, Siddiqui AH, Crumlish A, et al. First Food and Drug Administration-approved prospective trial of primary intracranial stenting for acute stroke: SARIS (stent- assisted recanalization in acute ischemic stroke). Stroke 2009; 40:3552-3556.

18. Smith SC Jr, Feldman TE, Hirshfeld JW, et al. ACC/ AHA/SCAI 2005 Guideline update for percutaneous coronary intervention: summary article: a report of the American College of Cardiology/American Heart Association Task Force on Practice Guidelines. Circulation 2006; 113:156-175.

19. Hochholzer W, Trenk D, Frundi D, et al. Time dependence of platelet inhibition after a 600-mg loading dose of clopidogrel in a large, unselected cohort of candidates for percutaneous coronary intervention. Circulation 2005; 111:2560-2564.

20. Von Beckerath N, Taubert D, Pogatsa-Murray G, et al. Absorption, metabolization, and antiplatelet effects of 300-, 600-, and 900-mg loading doses of clopidogrel: results of the ISAR-CHOICE Trial. Circulation 2005;112: 2946-2950.

21. Montalescot G, Sideris G, Meuleman C, et al. A randomized comparison of high clopidogrel loading doses in patients with non-ST-segment elevation acute coronary syndromes: the ALBION trial. J Am Coll Cardiol 2006; 48:931-938.

22. Cuisset T, Frere C, Quilici J, et al. Benefit of a 600-mg loading dose of clopidogrel on platelet reactivity and clinical outcomes in patients with non-ST-segment elevation acute coronary syndrome undergoing coronary stenting. J Am Coll Cardiol 2006;48:1339-1345.

23. Suri MF, Hussein HM, Abdelmoula MM, Divani AA, Qureshi AI. Safety and tolerability of $600 \mathrm{mg}$ clopidogrel bolus in patients with acute ischemic stroke: preliminary experience. Med Sci Monit 2008;14:PI39-PI44.

24. Collet JP, Hulot JS, Pena A, et al. Cytochrome P450 2C19 polymorphism in young patients treated with clopidogrel after myocardial infarction: a cohort study. Lancet 2009; 373:309-317.

25. Roden DM, Stein CM. Clopidogrel and the concept of high-risk pharmacokinetics. Circulation 2009;119:21272130 .

26. Sibbing D, Stegherr J, Latz W, et al. Cytochrome P450 2C19 loss-of-function polymorphism and stent thrombosis following percutaneous coronary intervention. Eur Heart J 2009;30:916-922.

27. Simon T, Verstuyft C, Mary-Krause M, et al. Genetic determinants of response to clopidogrel and cardiovascular events. N Engl J Med 2009;360:363-375.

28. Mega J, Close S, Wiviott $S$, et al. Cytochrome $\mathrm{p}-450$ polymorphisms and response to clopidogrel. N Engl J Med 2009;360:354-362.

29. Price MJ, Berger PB, Teirstein PS, et al. Standard- vs highdose clopidogrel based on platelet function testing after percutaneous coronary intervention: the GRAVITAS randomized trial. JAMA 2011;305:1097-1105.

30. Bhatt DL. Tailoring antiplatelet therapy based on pharmacogenomics: how well do the data fit? JAMA 2009;302: 896-897.

31. Yousuf O, Bhatt DL. The evolution of antiplatelet therapy in cardiovascular disease. Nat Rev Cardiol 2011;8:547559.

32. Prasugrel package insert. Available at: http://pi.lilly.com/ us/effient.pdf. Accessed October 9, 2011.

33. Wiviott SD, Braunwald E, McCabe $\mathrm{CH}$, et al. Prasugrel versus clopidogrel in patients with acute coronary syndromes. N Engl J Med 2007;357:2001-2015. 
34. Mandava P, Thiagarajan P, Kent TA. Glycoprotein IIb/ IIIa antagonists in acute ischaemic stroke. Drugs 2008;68: $1019-1028$.

35. Lee DH, Jo KD, Kim HG, et al. Local intraarterial urokinase thrombolysis of acute ischemic stroke with or without intravenous abciximab: a pilot study. J Vasc Interv Radiol 2002;13:769-773.

36. Abou-Chebl A, Bajzer CT, Krieger DW, et al. Multimodal therapy for the treatment of severe ischemic stroke combining GPIIb/IIIa antagonists and angioplasty after failure of thrombolysis. Stroke 2005;36:2286-2288.

37. Deshmukh VR, Fiorella DJ, Albuquerque FC, et al. Intraarterial thrombolysis for acute ischemic stroke: preliminary experience with platelet glycoprotein IIb/IIIa inhibitors as adjunctive therapy. Neurosurgery 2005;56:46-55.

38. Mangiafico S, Cellerini M, Nencini P, et al. Intravenous glycoprotein IIb/IIIa inhibitor (tirofiban) followed by intra-arterial urokinase and mechanical thrombolysis in stroke. AJNR Am J Neuroradiol 2005;26:2595-2601.

39. Eckert B, Koch C, Thomalla G, et al. Aggressive therapy with intravenous abciximab and intra-arterial rtPA and addition PTA/stenting improves clinical outcome in acute vertebrobasilar occlusion: combined local fibrinolysis and intravenous abciximab in acute vertebrobasilar stroke treatment (FAST): results of a multicenter study. Stroke 2005;36:1160-1165.

40. Qureshi AI, Harris-Lane P, Kirmani JF, et al. Intra-arterial reteplase and intravenous abciximab in patients with acute ischemic stroke: an open-label, dose-ranging, phase I study. Neurosurgery 2006;59:789-797.

41. Lee KY, Heo JH, Lee SI, Yoon PH. Rescue treatment with abciximab in acute ischemic stroke. Neurology 2001;56: 1585-1587.

42. Smith WS. Safety of mechanical thrombectomy and intravenous tissue plasminogen activator in acute ischemic stroke: results of the Multi Mechanical Embolus Removal in Cerebral Ischemia (MERCI) trial, part I. AJNR Am J Neuroradiol 2006;27:1177-1182.

43. Walsh RD, Barrett KM, Aguilar MI, et al. Intracranial hemorrhage following neuroendovascular procedures with abciximab is associated with high mortality: a multicenter series. Neurocrit Care 2011;15:85-95.

44. Chen ZM, Sandercock P, Pan HC, et al. Indications for early aspirin use in acute ischemic stroke: a combined analysis of 40000 randomized patients from the Chinese acute stroke trial and the international stroke trial: on behalf of the CAST and IST collaborative groups. Stroke 2000;31: $1240-1249$

45. The National Institute of Neurological Disorders and Stroke rt-PA Stroke Study Group. Tissue plasminogen activator for acute ischemic stroke. N Engl J Med 1995;333: 1581-1587.

46. Hacke W, Kaste M, Bluhmki E, et al. Thrombolysis with alteplase 3 to 4.5 hours after acute ischemic stroke. N Engl J Med 2008;359:1317-1329. 


\section{Neurology}

\section{Periprocedural antithrombotic strategies in acute ischemic stroke interventional therapy \\ Fadi Nahab, Tareq Kass-Hout and Hashem M. Shaltoni \\ Neurology 2012;79;S174-S181 \\ DOI 10.1212/WNL.0b013e31826959af}

This information is current as of September 24, 2012

\section{Updated Information \&} Services

References

Citations

Subspecialty Collections

Permissions \& Licensing

Reprints including high resolution figures, can be found at: http://n.neurology.org/content/79/13_Supplement_1/S174.full

This article cites 42 articles, 15 of which you can access for free at: http://n.neurology.org/content/79/13_Supplement_1/S174.full\#ref-list1

This article has been cited by 4 HighWire-hosted articles: http://n.neurology.org/content/79/13_Supplement_1/S174.full\#\#otherar ticles

This article, along with others on similar topics, appears in the following collection(s):

All Cerebrovascular disease/Stroke

http://n.neurology.org/cgi/collection/all_cerebrovascular_disease_strok e

Information about reproducing this article in parts (figures,tables) or in its entirety can be found online at:

http://www.neurology.org/about/about_the_journal\#permissions

Information about ordering reprints can be found online:

http://n.neurology.org/subscribers/advertise

Neurology ${ }^{\circledR}$ is the official journal of the American Academy of Neurology. Published continuously since 1951, it is now a weekly with 48 issues per year. Copyright Copyright $@ 2012$ by AAN Enterprises, Inc.. All rights reserved. Print ISSN: 0028-3878. Online ISSN: 1526-632X.

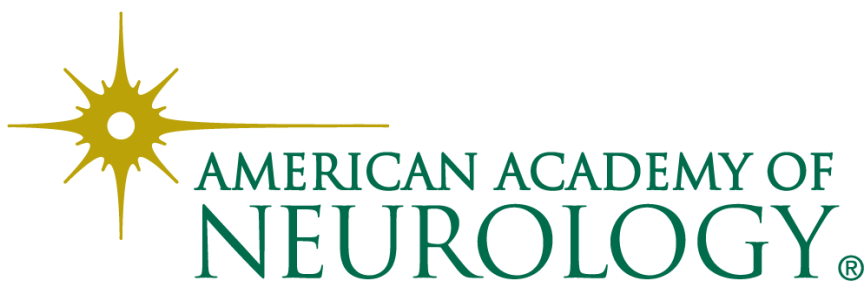

